\title{
Research on Application of Goal-setting Teaching Method in Badminton Elective Course in Common Colleges and Universities
}

\author{
Shouwen Wang \\ Heihe University \\ Heihe, China
}

\author{
Zhentao Liu \\ Heihe University \\ Heihe, China
}

\begin{abstract}
With the development and reform of elective courses in colleges, badminton has gradually spread to the physical education elective courses in colleges, becoming one of the sports popular among college students. At present, the goalsetting teaching method has been used more and more widely in badminton elective course teaching in common colleges and universities, through the research on application of goal-setting teaching method in badminton elective course teaching in common colleges and universities, it is found that goal-setting teaching method can improve the efficiency of elective course teaching, cultivate the students' interest and enthusiasm in learning and improve their overall level of badminton. Taking the literature as research basis, and combining with the questionnaire, this paper makes specific analyzing of the application of goal-setting teaching method in badminton elective course teaching in common colleges and universities.
\end{abstract}

Keywords—goal-setting teaching method; colleges; badminton; elective course

\section{INTRODUCTION}

Badminton has long been popular with the students, and as an important course of sports in common colleges and universities, badminton elective course has been selected by a large number of students. But in common colleges and universities, teachers and students generally pay attention to the professional courses, yet the elective courses such as badminton is neglected by the colleges and teachers, as a result, students have poor performance in badminton elective course, and they just learn with interest but without professional teaching method. If this trend continues, it will be bad for students' moral, intellectual, physical and beauty development. In the context of modern course reform, teachers must transform the teaching concept in the process of teaching and adopt the goal-setting teaching mode, cultivate students' active learning and creative learning ability, strive to improve the teaching quality of badminton elective course in colleges, and pay attention to the teaching of physical education, deepen teaching reform, optimize the teaching plan, and make efforts to create a new goal-setting teaching system.

\section{BASiC CONCEPT OF GOAL-SETting TEACHING MethoD}

Goal-setting teaching method mainly refers to that teachers set a teaching goal and students study following the teaching clues. Goal-setting teaching method mainly takes students as the main body. Teachers set the targets, organize and guide the students to learn, explain the professional knowledge, technical skills and competitive tactics of badminton in detail in each course, control teaching content step by step, make students understand what they have learned, and at the same time, have a clear understanding of students' proficiency, and provide the targeted teaching according to the academic requirements. Such goal-setting teaching mode has the following important features: First, it can provide targeted guidance to each student, subdivide the knowledge, and make the teaching process controllable. Second, teachers must set clear teaching tasks in classroom, and have certain understanding of the specific process and results of this teaching task, and make sure the task can be completed by the students independently, to cultivate their interest in learning and sense of achievement. Third, such teaching method is more humane, as it takes students as the main body, and respect students' self-esteem.

\section{CURRENT SituAtion OF BADMINTON EleCtive COURSE TEACHING IN COMMON COLLEGES AND UNIVERSITIES}

\section{A. Current situation of Badminton Elective Course Development}

Badminton is a sport deeply loved by young students. This sport is easy to be conducted, and has quite low requirements for space, requiring only two people, having the effect of entertainment and fitness, which can improve students' overall physical quality. Because it has strong flexibility and is easy to operate, so it develops widely in common colleges and universities, being the sport item selected by many college students with preference among physical education elective courses.

\section{B. Learning Situation of Badminton Elective Course of College Students}

Badminton elective course mainly gives priority to practice, requiring students to practice, and teachers only teach some basic theoretical knowledge, such as: position posture, ways to hit the ball and methods to hold the racket. But there are a lot of students having weak basic knowledge of badminton, and they are difficult to practice badminton correctly. 200 questionnaires in total are granted to 200 students, who have 
selected badminton from school of physical education, and 200 questionnaires are recovered, namely the questionnaire recovery rate is up to $100 \%$, including 128 boys and 72 girls.

According to the questionnaire, 97 students have learned badminton before with certain foundation, 82 students have learned little about badminton with weak badminton foundation knowledge, and 21 students haven't learned badminton at all, indicating that the students' basic level of badminton is uneven with different purposes. Although the goal-setting teaching method has been applied, and teachers conduct specific teaching against each course, there still exists different mastery degree of knowledge in actual teaching process, as some students accept the badminton professional knowledge quickly and improve technical level fast, so that they can achieve excellent achievements. Some other students have difficulty in learning badminton and improving their technical level, leading to the students lose interest and confidence in learning, which has influenced the teaching quality.

There are $42 \%$ students think badminton is an elegant recreational sport, which can bring pleasure to physical education, and has enriched their college life, therefore, they have interest in badminton elective course. $25 \%$ of students think badminton can fortify their health, thus they select badminton course to do physical exercise. $20 \%$ of the students select badminton course only for the purpose to obtain credits. The other $13 \%$ of the students have no clear goal while choosing sports elective courses, and they just select badminton elective course because their friends and classmates have selected this course, so they are not familiar with basic knowledge of badminton. The traditional teaching mode can't meet the learning demand of the majority of students, and the course model reform of badminton is needed.

\section{Faculty of Badminton Elective Course in Colleges and Universities}

A lot of students select badminton because they love it, and this has resulted in a serious shortage of teachers. Thus there is such case as one teacher teaches several classes simultaneously, so the teacher cannot conduct specific teaching for each class and can't grasp the students' learning situation. Some teachers take charge of the students purely for wages, and they make students to exercise freely in class. Many PE teachers are the professional personnel recruited directly from the society, though they have profound badminton professional knowledge and skills, they have insufficient teaching methods and teaching contents, which is bad for guiding students' badminton, and cannot teach starting from the basic ones, as they tend to use some professional terms that students do not understand, reducing the teaching efficiency. Students have poor badminton foundation, and they choose badminton course completely out of their hobbies and interests. If teachers cannot mobilize students' interest in learning, students will gradually lose confidence.

\section{Training Ground and Equipment of Badminton Elective Course in Colleges and Universities}

As for badminton elective course, the training ground and equipment are the basic conditions to complete teaching, which influence students' learning progress directly to a large extent and limit the teaching mode. Through the survey on actual teaching of badminton elective course in part of the colleges and universities, we can know that many classes share one training ground, and lack of a lot of rackets, only a small number of students exercise in pair, most of the students exercise outside the ground or at the edge of the ground. The shortage of training grounds and equipment has influence the normal teaching, and is difficult to meet students' demand of the course.

\section{PROBLEMS EXIST IN TRADITIONAL BADMINTON TEACHING}

\section{A. Simple Teaching Content}

Badminton is a sport with fast changes, as the patting of the ball is flexible with different distances and heights as well as the degrees, testing one's technology and physical coordination. But students only pay attention to the entertainment and fitness and neglect the patting technology, which is difficult to conduct professional badminton. In traditional teaching of badminton, teachers pay attention to a certain technology grasped by students, and they make students repeat a single action, gradually students will feel bored. In the badminton elective course, teachers simply let the student to do warm-up exercises first, and then exercise freely, and they don't check each student's learning effect seriously when the class is over, which has made students have no learning motivation, learning objective and the enthusiasm of self-study toward badminton elective course. Many teachers of badminton elective course don't teach seriously, and they are reluctant to make efforts to research the teaching contents and just require the students to learn as per what is stipulated in the teaching materials. Thus students' level of badminton will never be really improved, and students will always stay at the point of entertaining.

\section{B. Unreasonable Course Evaluation}

Teachers' evaluation methods of badminton elective course at the end of the semester are simple, which are only divided into technical appraisal and up to standard. They organize the students to participate in competition of badminton, and determine the exam results according to the results of competition, without a professional standard, and haven't evaluated students' usual learning attitude and their own ability. Because of physical quality, some students are unable to grasp the professional and technical actions even if they practice very hard, while the students with good physical condition can obtain good results although they haven't practiced strictly, this is very unfair to students with poor physical quality, influencing their learning attitude and motivation seriously. 


\section{Outdated Teaching Concept and Deficient Teaching Environment}

Many teachers of badminton elective course in common colleges and universities are the retired badminton players, who have the relatively old teaching concept and teaching method, and it is difficult for them carry out "student oriented" goal-setting teaching method, which has not only affected the development of goal-setting teaching mode, but also has limited the students' innovative thinking. PE teachers lack the teaching practice knowledge, and haven't mastered the advanced goal-setting teaching method, making students have no motivation in badminton elective course, which has affected the teaching quality. Some colleges conduct badminton teaching in stadium, which is difficult to make students to realize the real charm of badminton. Teaching quality will be reduced greatly without corresponding teaching environment.

\section{APPLICATION SigNIFICANCE OF GOAL-SETTING Teaching Method in Badminton Elective Course TEACHING IN COLLEGES}

Because the students who select badminton have different professional knowledge, technological base and physical quality, so the significance of goal-setting teaching method applied in badminton elective course is different too.

\section{A. Positive Significance}

Goal-setting teaching method can refine the teaching content and make students understand their learning task and learning goals, thus stimulate students' learning interest and enthusiasm. Teachers divide the teaching objectives into groups according to different students' basic situation, and set different learning objectives and tasks against different students, to fully respect each student's study psychology and make students' learning more targeted, so as to fully exploit each student's specialty and cultivate their interests. For example, as for some students with good physical quality and strong badminton professional basis, the goal for them can be set high, and make them participate in competitive training, so that they are able to learn from each other of the skills and tactics with the students having same level with them, and make up their own technical vulnerabilities. As for some students with poor physical quality and weak professional basic knowledge, they shall be taught separately, first of all, ask them to understand the basic knowledge of badminton and technical method, and then adjust the teaching against students' disadvantages. Teachers shall be humorous in teaching and infuse some delightful elements into the sports, to mobilize class atmosphere, and attract student with teacher's personality charm, enable students to experience the fun of badminton. As for some wrong actions in badminton competition, teachers shall explain with demonstration against students' actions, so that students can find their own problems quickly and improve their level of technical actions.

\section{B. Negative Effect}

Differences exist in students' physical quality, personality characteristics and technical level, so some students may not be able to adapt to the goal-setting teaching method in terms of the refined teaching contents, or even they cannot understand the contents of some courses, as a result, their negative psychology and resistance will appear. The students with strong technical foundation will feel tired, boring and wasting time and energy while learning some basic knowledge, consequently, their learning enthusiasm will be reduced and learning process will be restricted. For example, while learning the basic gripping and service methods, the students with good foundation are required to save the ground and equipment to those students with weak foundation, so they have to stand by and just watch which made the learning unfair. Some other student have no interest in badminton lack the learning enthusiasm, and have negative attitude toward learning, and they don't listen to the guidance of the teacher and just follow their own will, and they participate in the training only for coping with the teachers. At the same time, they also affect some students with weak will, and it is easy to form a chain reaction among the students. Moreover, many female students with poor physical quality tend to avoid training by asking for leave, as they have no interest in badminton learning. The goal-setting teaching approach makes course stricter, which is not conform to the physical education standard in the mind of college students. Influenced by traditional physical education, students still like free practice in the classroom with bad teaching effect.

\section{SUGGESTIONS FOR IMPROVING THE APPLICATION EFFECT OF GOAL-SETTING TEACHING APPROACH IN Badminton Elective Course TeACHING In Colleges AND UNIVERSITIES}

\section{A. Set the Teaching Content according to Students' Interest}

Teachers can set the teaching content according to students' interest and refine the cultivation of student's badminton technology. Discover students' interest, and may be it the badminton star loved by the students can be taken as the entry point. In the teaching process, the technical characteristics of badminton star can be brought into the teaching content, make students learn the badminton technology of the star they like, so as to cultivate the students' interest in learning and improve their skill levels. For example, some students like Lin Dan, so Lin Dan's method of gripping by left hand LaDiao assault can be explained as a key teaching point, to enable students to fully understand the main technical points of this skill. Competitions can be carried out frequently in the badminton classroom, to stimulate students' learning enthusiasm through incentives. And students can also find their own shortcomings in the competition and make corrections. Teachers can also record students' competition situation alongside, and then provide guidance according to their specific situation. This kind of learning can improve students' level of badminton faster and better, and by integrating studying and training into competition, the teaching effect can be improved.

\section{B. Refine the Teaching, and Teach according to Their Aptitude}

Refine the badminton teaching content and mode, and separate the students with strong technical foundation and 
those with poor foundation and help them develop the confidence in learning badminton. And the students with good performances shall be praised and encouraged. Summarize students' learning situation, as for the differences within students, teachers shall give the praise of different levels to them, as well as respect students' learning outcomes, and protect their self-esteem. Strictly grasp the learning situation of each student, and teach the students according to their aptitude. Those students with poor performances and love to play shall not be ignored.

\section{CONCLUSION}

It can be learned from the above analysis and research that, the goal-setting teaching method may improve the teaching effect if it is used properly in badminton elective course teaching. In the actual teaching, teachers shall also improve the teaching method constantly, supervise and urge students to do physical exercise. Cultivate each student's badminton techniques comprehensively, to lay a solid foundation for students' development in the future in terms of body.

\section{REFERENCES}

[1] Zeng Yongzhong. Experimental Research on Influence of Teaching Games for Understanding on Higher Vocational Students' Learning of Badminton Selective Course [J]. Fujian Sports Science and Technology, 2011, 05: 29-32.

[2] Ling Liping, Shang Ruihua, Wu Donghai. Experimental Research on Teaching Effect of Competition Teaching Method on Badminton Selective Course in Colleges [J]. Fighting (Sports Forum), 2012, 03: 44-45.

[3] Tan Junhui. Application Research on Level-grading Teaching Method in Badminton Teaching in Common Colleges and Universities [J]. Sports World, 2013, 11:116-117.

[4] Zhang Bin. Reflection on Badminton Course System Construction in Common Colleges and Universities in Henan Province [J]. Journal of Henan Institute of Education (Natural Science Edition), 2013,01: 77-80. 